\title{
Impact of Potassium on Gasification Reaction and Post-Reaction Strength of Ferro-coke
}

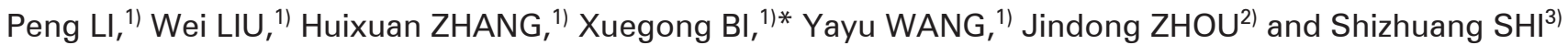 \\ 1) State Key Laboratory for Refractory Materials and Metallurgy, Wuhan University of Science and Technology, Wuhan, Hubei, \\ 430081 China. $\quad 2$ ) Key Laboratory for Ferrous Metallurgy and Resources Utilization of Ministry of Education, Wuhan \\ University of Science and Technology, Wuhan, Hubei, 430081 China. $\quad 3)$ Key Laboratory for Coal Conversion and \\ Advanced Carbon Materials of Hubei Province, Wuhan University of Science and Technology, Wuhan, Hubei, 430081 China.
}

(Received on May 26, 2017; accepted on July 12, 2017; J-STAGE Advance published date: September $28,2017)$

\begin{abstract}
Ferro-coke is an advanced kind of coke, to clarify the behavior of its gasification affected by alkalis is very important for its practical use in blast furnace. In this paper, potassium was added to sample by soaking and boiling it in $\mathrm{K}_{2} \mathrm{CO}_{3}$ aqueous solution, the variation of coke weight loss vs time was measured with the thermogravimetry approach, the Tablets Coke Method was applied for measurement of the reactivity and post-reaction strength of cokes, and the gasification reaction mechanism was analyzed based on the Shrinking-Core Model (SCM). This work demonstrated that potassium had a catalytic effect on ferro-coke gasification in terms of a decrease in the starting reaction temperature and reaction activation energies. In comparison with traditional coke, when no $\mathrm{K}_{2} \mathrm{O}$ was added, the reactivity index of ferro-coke was higher and the post-reaction strength index of ferro-coke was lower, while as a same amount of $\mathrm{K}_{2} \mathrm{O}$ was added and in respect to these two indices, the direction of variation of ferro-coke was the same and the extent of variation of ferro-coke was slightly higher. Different from traditional coke, when temperature ranges from 950 to $1050^{\circ} \mathrm{C}$ and the degree of burning-off is within $50 \%$, the reaction of ferro-coke is always mixed controlled by chemical reaction and inner diffusion.
\end{abstract}

KEY WORDS: ferro-coke; potassium; gasification reaction; shrinking-core model; thermal properties.

\section{Introduction}

Ferro-coke refers to a special metallic iron-containing coke that is prepared by the preliminary grinding, mixing and forming of iron ores and coals and the subsequent carbonizing. Its reactivity with $\mathrm{CO}_{2}$ substantially exceeds traditional coke due to the catalytic effect of iron. ${ }^{1,2)}$ Use of highly reactive cokes, including ferro-coke, could improve blast furnace reaction efficiency and decrease energy consumption. ${ }^{3,4)}$ The primary cause is that ferro-coke gasifies at lower temperatures, meaning the temperature of the thermal reserve zone is lower, the equilibrium concentration of $\mathrm{CO}$ is smaller and hence the difference between the $\mathrm{CO}$ content in gases and its equilibrium value is greater. This will then accelerate the indirect reduction of iron ores and improve the blast furnace efficiency. Nippon Steel \& Sumitomo Metal Corporation made a study of producing ferro-coke by means of the traditional top-charging cokemaking technology and carried out an industrial trail in a single battery. ${ }^{5)}$ JFE applied the briquetting/shaft furnace process to prepare ferro-coke, and at the end of $2012 \mathrm{FY}, 5$ day and $43 \mathrm{~kg} / \mathrm{t}$ ferro-coke charging test was conducted at Chiba BF No. 6 and reduction of RAR (abbreviation of Reducing Agent

* Corresponding author: E-mail: 1575595611@qq.com

DOI: http://dx.doi.org/10.2355/isijinternational.ISIJINT-2017-292
Ratio) by $13-15 \mathrm{~kg} / \mathrm{t}$ was successfully confirmed. ${ }^{6}$

Coke is the universal fuel used in the blast furnace. Apart from providing reactants and heat and carburizing liquid iron, the roles that coke plays also include providing permeability (in the dry as well as the wet zones) and mechanical support to the large charge column, permitting the gases to ascend through the voids. ${ }^{7)}$ This is because coke is the only charge material that keeps a solid form at high temperatures in the lower furnace. The strength and the reactivity of coke have a good negative correlation. In general, due to the addition of inert material iron ores, the cold strength, i.e. wearing-resistant index $\mathrm{M}_{10}$ and breaking-resistant index $\mathrm{M}_{40}$, and the thermal strength or post-reaction strength index CSR of ferro-coke are all inferior to traditional coke. Yet, by means of optimizing the blending ratio of gas-fat coal and iron ore, increasing the bulk density of coal charge and controlling the appreciate carbonizing temperatures, it is expected to decrease the extent of CSR declining with CRI (the reactivity index) increasing, i.e. to maintain a higher thermal strength at a same degree of burning-off. In the laboratory, authors of this paper applied the stamping charge technique and prepared ferro-coke samples with fairly good cold strengths and thermal properties: $\mathrm{M}_{10}$ was about $9 \%$, $\mathrm{M}_{25}$ was about $85 \%$, CRI was about $56 \%$ and CSR was about $64 \%$. These quality indices are comparable to the industrial coke fed into the $2500 \mathrm{~m}^{3} \mathrm{BF}$ in the Xinjiang 
Bayi Iron and Steel Company, Baosteel.

As is well known, there is alkali vapor circulating in the blast furnace. The laboratory investigations demonstrated that alkali circulation greatly affects the coke properties, i.e. improving reactivity, ${ }^{8-10)}$ decreasing strength and worsening size degradation. Note that size degradation is not only caused by the increase in reactivity but more importantly also by the disintegration of coke. ${ }^{10)}$ This agrees with the measurements of chemical composition and properties of coke samples taken from the nitrogen quenched blast furnaces in 1977. ${ }^{11)}$ The consequence of a decrease in strength and an increase in size degradation would be the worsening of stock permeability, a decrease in furnace throughput and an increase in RAR.

Up to now, there aren't many investigations into the impact of alkalis on the gasification reaction and strength property of ferro-coke. Nomura et al. ${ }^{12)}$ studied the influence of a specified amount of $\mathrm{K}$ on the starting reaction temperature of three formed ferro-coke samples with different total iron content. In the tests, a $\mathrm{CO}_{2}$ and $\mathrm{CO}$ mixture was introduced. The temperature where the differential weight loss is consistently higher than $0.002 / \mathrm{min}$ was defined as the starting reaction temperature. Their work demonstrated that the starting gasification temperature decreased with increasing the total Fe content and this extent of decrease became smaller when potassium was added.

Coke reactivity, during its passage through the furnace, the manner in which the coke reacts could markedly influence its degradation characteristics and hence the performance of the furnace as a whole. It would be clearly desirable to forecast the effect of the gasification characteristics of coke on the blast furnace performance, and then to optimize it by optimizing the coke gasification characteristics. This motivated many researchers to study the kinetics of coke gasification reaction. It was reported by many researchers that the measured kinetics parameters are highly specific to experimental conditions, such as temperature level and heating program, gas composition and flow rate, size and shape of the sample, etc. For this reason, only those results in the literature by using pellets or pieces of coke were cited in this paper for making a comparison with our work.

Szekely et al. ${ }^{13)}$ utilized the Langmuir-Hinshelwood model for kinetics analysis. They created correlation expression of three rate constants and temperature, and introduced three adjustable parameters in the L-H model. To address the experimental uncertainty resulting from industrial coke's complexity and heterogeneity when it is used in experimental studies, Jayasekara et al. ${ }^{14)}$ prepared a coke analogue by using laboratory graphite mixed with resins. Their kinetics analysis was based on the Arrhenius model and accessed activation energies for three zones and the transition zones. Taking the Shrinking-Core Model (SCM ${ }^{15}$ ) as a base, Cui et al. ${ }^{16)}$ assessed the reaction activation energy as well as the diffusion activation energy.

Nomura et al. ${ }^{17-19)}$ studied gasification reaction and post-reaction strength of catalyst-loaded ferro-coke. In this paper, focused on ferro-coke, the thermogravimetry (TG) technique was applied to the measurement of the starting gasification temperature of coke and to the analysis of reaction kinetics, and the Tablets Coke Method was applied to the measurement of the reactivity and the post-reaction strength of coke. The catalytic effect of potassium on gasification reaction and the impact on the thermal properties for ferro-coke were quantitatively confirmed and the results were also compared to the traditional coke.

\section{Experimental Study}

\subsection{Experimental Samples}

Traditional coke and ferro-coke samples were prepared in the $6 \mathrm{~kg}$ experimental coke oven of Wuhan University of Science and Technology, the industrial coal blends from Wuhan Allied Cokemaking Company of Pingmei and Wugang were directly used for the traditional coke preparation while for the ferro-coke preparation $10 \%$ Canadian iron concentrate was mixed into the industrial coal blends. The properties of the coal blend and iron concentrate are respectively presented in Tables $\mathbf{1}$ and $\mathbf{2}$. The stamping charge technique was applied to control the bulk density of coal charge at about $1.1 \mathrm{~kg} / \mathrm{cm}^{3}$ and the discharged coke was quenched with water. The prime properties of coke samples are shown in Tables 3 and $\mathbf{4}$.

The sample was put into an aqueous solution of 10 mass $\% \mathrm{~K}_{2} \mathrm{CO}_{3}$ and then boiled, coke samples with different amount of potassium addition were prepared by adjusting the boiling time. For the measurement of the starting gasification temperature of ferro-coke and the study of its

Table 1. Basic properties of coal blend.

\begin{tabular}{cccccccc}
\hline $\begin{array}{c}\mathrm{M}_{\mathrm{ad}} \\
\text { mass\% }\end{array}$ & $\begin{array}{c}\mathrm{A}_{\mathrm{d}} \\
\text { mass\% } \%\end{array}$ & $\begin{array}{c}\mathrm{V}_{\mathrm{d}} \\
\text { mass\% }\end{array}$ & $\begin{array}{c}\mathrm{S}_{\mathrm{t.d}} \\
\text { mass\% }\end{array}$ & G & $\lg M F$ & $\mathrm{Y} \mathrm{mm}$ & $\lg M F$ \\
\hline 1.70 & 9.41 & 27.95 & 0.818 & 86.38 & 3.01 & 16 & 3.12 \\
\hline
\end{tabular}

Note: $\mathrm{M}_{\mathrm{ad}}, \mathrm{A}_{\mathrm{d}}, \mathrm{V}_{\mathrm{d}}$ and $\mathrm{S}_{\mathrm{t} . \mathrm{d}}$ is respectively the moisture, ash, volatile matter and total sulfur content; $\mathrm{G}$ is the caking property index, $\mathrm{Y}$ is the thickness of colloids layer, $\lg M F$ is (Gieseler) fluidity index converted from $\mathrm{G}$, $\lg M F^{\prime}$ is (Gieseler) fluidity index converted from Y.

Table 2. Chemical composition of Canadian iron concentrate.

\begin{tabular}{ccccccccccc}
\hline Component & $\mathrm{T} . \mathrm{Fe}$ & $\mathrm{FeO}$ & $\mathrm{SiO}_{2}$ & $\mathrm{Al}_{2} \mathrm{O}_{3}$ & $\mathrm{CaO}$ & $\mathrm{MgO}$ & $\mathrm{S}$ & $\mathrm{P}$ & $\mathrm{K}_{2} \mathrm{O}$ & $\mathrm{Na}_{2} \mathrm{O}$ \\
\hline Content & 66.50 & 0.82 & 3.97 & 0.27 & 0.08 & 0.01 & 0.022 & 0.020 & 0.001 & 0.001 \\
\hline
\end{tabular}

Table 3. Basic properties of the coke samples.

\begin{tabular}{ccccccccc}
\hline Sample & Metallization rate, $\%$ & $\mathrm{~A}_{\mathrm{d}}$ mass $\%$ & $\mathrm{~S}_{\mathrm{t.d}}$ mass $\%$ & $\mathrm{~V}_{\mathrm{d}}$ mass $\%$ & $\rho_{a} \mathrm{~g} \cdot \mathrm{cm}^{-3}$ & $\rho_{t} \mathrm{~g} . \mathrm{cm}^{-3}$ & $P_{t} \mathrm{vol}_{0}$ & $P_{a} \mathrm{vol}_{0}$ \\
\hline Traditional coke & 45.00 & 13.44 & 0.56 & 1.72 & 1.02 & 1.96 & 47.76 & 38.03 \\
Ferro-coke & 57.98 & 25.47 & 0.61 & 1.33 & 1.07 & 2.12 & 48.96 & 40.46 \\
\hline
\end{tabular}

Note: $\rho_{a}$ is the apparent density, $\rho_{t}$ is the true density; $P_{t}$ is the total porosity, $P_{a}$ is the open porosity. 
Table 4. Chemical composition of the coke samples (mass\%).

\begin{tabular}{ccccccccc}
\hline Sample & M.Fe & T.Fe & $\mathrm{K}_{2} \mathrm{O}$ & $\mathrm{CaO}$ & $\mathrm{SiO}_{2}$ & $\mathrm{Al}_{2} \mathrm{O}_{3}$ & $\mathrm{MgO}$ & $\mathrm{Fe}_{2} \mathrm{O}_{3}$ \\
\hline $\begin{array}{c}\text { Traditional } \\
\text { coke }\end{array}$ & 0.27 & 0.60 & 0.10 & 0.52 & 5.33 & 9.87 & 0.21 & 1.90 \\
$\begin{array}{c}\text { Ferro-coke } \\
5.23\end{array}$ & 9.02 & 0.081 & 0.51 & 6.14 & 5.06 & 0.13 & 12.27
\end{tabular}

Table 5. Scheme of potassium addition of ferro-coke.

\begin{tabular}{ccccc}
\hline Experiment & $\begin{array}{c}\text { Run } \\
\text { no. }\end{array}$ & $\begin{array}{c}\mathrm{K}_{2} \mathrm{CO}_{3}, \\
\text { mass\% }\end{array}$ & $\begin{array}{c}\text { Boiling } \\
\text { time, min }\end{array}$ & $\begin{array}{c}\mathrm{K}_{2} \mathrm{O}, \\
\text { mass } \%\end{array}$ \\
\hline $\begin{array}{c}\text { A-1 } \\
\text { Atarting reaction }\end{array}$ & A-3 & 10 & - & 0.08 \\
temperature measurement & A-4 & 10 & 45 & 0.95 \\
& A-5 & 10 & 60 & 1.38 \\
& B-1 & - & - & 0.08 \\
\hline & & 10 & 15 & 0.93 \\
Reaction kinetics study & B-2 & 10 & 15 & 0.95 \\
\hline
\end{tabular}

Note: B-1 is the sample without potassium addition; B-2 is the sample with potassium addition, its mean $\mathrm{K}_{2} \mathrm{O}$ content is $0.937 \%$.

reaction kinetics, the potassium addition scheme listed in Table 5 was accepted.

\subsection{Starting Reaction Temperature Measurement}

The experimental apparatus was a custom-made vertical tubular electric furnace with an isothermal zone of $70 \mathrm{~mm}$ in height. It usually worked at a temperature of $1100^{\circ} \mathrm{C}$, the error was $\pm 1^{\circ} \mathrm{C}$. The reaction tube (inner diameter $60 \mathrm{~mm}$ ) was made of quartz glass and alumina crucibles were used in the tests. The flow rate of reaction gases was controlled by LZ-A-15 version intelligent metal tube float flowmeters. An electronic balance of $0.001 \mathrm{~g}$ in precision was used for a continuous weighing. The real time data from the balance were recorded by a computer. The $\mathrm{CO}$ and $\mathrm{CO}_{2}$ concentrations in exhaust gases were analyzed by the Gas-board 3100 version infrared gas analyzer (Wuhan Tetragon Tech \& Sci. Co.).

The starting gasification temperature affects the size of the indirect reduction zone and is of a great importance for blast furnace operation. The weight of a ferro-coke sample dried for $2 \mathrm{~h}$ was $100 \pm 0.1 \mathrm{~g}$. It was added with potassium and then put into the furnace. The temperature was raised to $500^{\circ} \mathrm{C}$ at $10^{\circ} \mathrm{C} / \mathrm{min}$ under the protection of nitrogen gas at a flow rate of $0.1 \mathrm{~m}^{3} / \mathrm{h}$. After this, $\mathrm{N}_{2}$ was switched to $\mathrm{CO}_{2}$ $\left(0.18 \mathrm{~m}^{3} / \mathrm{h}\right)$, the gas analyzer was simultaneously turned on to analyze $\% \mathrm{CO}$ in the exhaust gases. When temperature reached the stated value, it was stopped to heat and started to introduce $\mathrm{N}_{2}$ for cooling. The temperature where $\% \mathrm{CO}$ in waste gases reached $1 \mathrm{vol} \%$ was defined as the starting gasification temperature in this work.

\subsection{Reactivity and Post-Reaction Strength Measure- ment}

The amount of a sample required in the Particles Coke Method (Chinese standard: GB/T 4000-1966) is large and therefore in this paper the Tablets Coke Method (GB 220-
77) was utilized for measuring the thermal properties of coke. The size of coke sample is 4 to $6 \mathrm{~mm}$. The sample was exposed to $1100^{\circ} \mathrm{C}$ and pure $\mathrm{CO}_{2}$ gas $\left(0.18 \mathrm{~m}^{3} / \mathrm{h}\right)$ for 2 $\mathrm{h}$. The reactivity index and the post-reaction strength index are respectively defined in Eqs. (1) and (2):

$$
\begin{gathered}
\mathrm{CRI}_{\mathrm{TCM}}(\%)=\left(m-m_{1}\right) / m \times 100 \\
\operatorname{CSR}_{\mathrm{TCM}}(\%)=m_{2} / m \times 100 \ldots .
\end{gathered}
$$

where $m$ is the coke mass prior reaction, $\mathrm{g} ; m_{1}$ is the coke mass after reaction, $\mathrm{g} ; m_{2}$ is the mass of coke larger than 3 $\mathrm{mm}$ after reaction, $\mathrm{g} ; \mathrm{CRI}_{\mathrm{TCM}}$ is reactivity by the Tablets Coke Method, \%; $\mathrm{CSR}_{\mathrm{TCM}}$ is post-reaction strength by the Tablets Coke Method, \%.

\subsection{Gasification Reaction Kinetics Experiment}

The experimental apparatus is the same as in Section 2.2. In a test, four pieces of traditional coke or ferro-coke dried at $105^{\circ} \mathrm{C}$ for $2 \mathrm{~h}$ in about same size were selected, totally weighing $5 \pm 0.03 \mathrm{~g}$. The sample was put into a metal wire basket and heated. For traditional coke, isothermal tests were carried out at $950^{\circ} \mathrm{C}, 1000^{\circ} \mathrm{C}$ and $1050^{\circ} \mathrm{C}$, respectively for 2 hours under pure $\mathrm{CO}_{2}$ gas, while for ferro-coke, isothermal tests were carried out also at $950^{\circ} \mathrm{C}$, $1000^{\circ} \mathrm{C}$ and $1050{ }^{\circ} \mathrm{C}$, respectively for 2 hours but under $\mathrm{CO}_{2}(19.4 \%)+\mathrm{CO}(26.3 \%)+\mathrm{N}_{2}(54.3 \%)$ gas mixture, simulating the condition in the blast furnace shaft.

It was discovered in the previous study of the authors ${ }^{20)}$ that, different from traditional coke, the weight of ferro-coke sample did not decrease but increased in the initial stage of reaction. This phenomenon is probably due to the occurrence of $\mathrm{Fe}+\mathrm{CO}_{2}=\mathrm{FeO}+\mathrm{CO}$ reaction. In this paper, for facilitating kinetics analysis, the data of weight increasing or no weight-loss in the initial phase of reaction were ignored. The degree of burning-off $R$ is represented as the weight loss percentage in the original fixed carbon mass prior reaction and calculated according to the following equation:

$$
R=\Delta m / m\left(1-\mathrm{A}_{\mathrm{d}}\right) \text {. }
$$

where $\Delta m$ is the weight loss, $\mathrm{g} ; m$ is the weight prior reaction, $\mathrm{g} ; \mathrm{A}_{\mathrm{d}}$ is the ash content of coke, $\%$.

\section{Results and Discussions}

\subsection{Impact of Potassium on Starting Gasification Tem- perature of Ferro-Coke}

It can be seen from Fig. 1 that with temperature increasing the $\mathrm{CO}$ content gradually increased. As the $\mathrm{CO}$ content reached about $1 \%$, the rising trend in the curves became noticeable. For this reason, the temperature where the $\mathrm{CO}$ content is equal to $1 \%$ is defined as the starting gasification temperature in this paper.

The starting gasification temperature of five ferro-cokes with different $\mathrm{K}_{2} \mathrm{O}$ content were evaluated according to Fig. 1, the results are depicted in Fig. 2. The starting gasification temperature of original ferro-coke A- 1 was $683^{\circ} \mathrm{C}$, while the starting gasification temperature of A-2, A-3, A-4 and A-5 were respectively $627^{\circ} \mathrm{C}, 622^{\circ} \mathrm{C}, 620^{\circ} \mathrm{C}$ and $617^{\circ} \mathrm{C}$ and their extents of decrease were respectively $56^{\circ} \mathrm{C}, 61^{\circ} \mathrm{C}, 63^{\circ} \mathrm{C}$ and $66^{\circ} \mathrm{C}$, demonstrating $\mathrm{K}$ decreased the starting gasification temperature of ferro-coke. Also can be seen in Fig. 1 when 


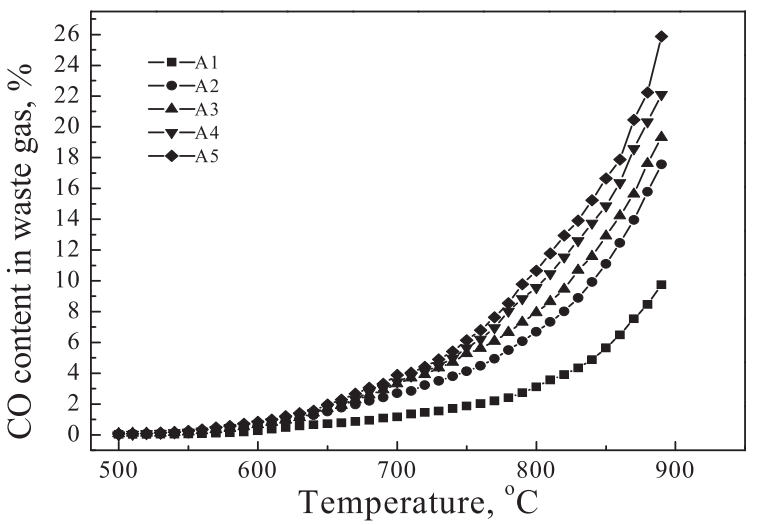

Fig. 1. Relationship between CO content in exhaust gas and temperature.

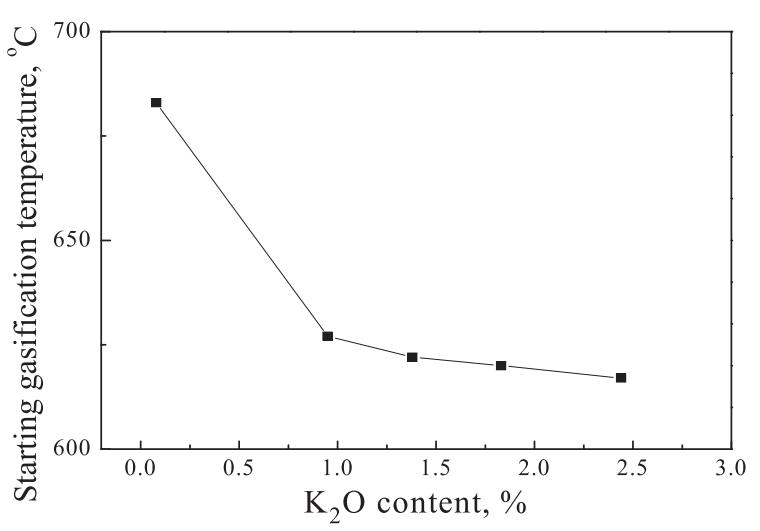

Fig. 2. Relationship between gasification starting temperature and potassium oxide content.

the $\mathrm{K}_{2} \mathrm{O}$ content did not exceed $0.95 \%$, the starting gasification temperature decreased sharply with increasing the $\mathrm{K}_{2} \mathrm{O}$ content, and that when the $\mathrm{K}_{2} \mathrm{O}$ content was beyond $0.95 \%$, the tendency of decrease obviously became gentle.

Reference [9] reported that for industrial coke supplied by Ma Steel Company, the starting gasification temperature decreased by near $100^{\circ} \mathrm{C}$ as $\mathrm{K}$-addition reached $1.0-1.2 \%$. However, in this work the gasification reaction of ferrocoke with $\mathrm{K}$ addition of $2.03 \%$ proceeded in advance only by $66^{\circ} \mathrm{C}$, showing that in respect to promoting gasification reaction, the effect of potassium on ferro-coke obviously is not as strong as on traditional coke. This conclusion agrees well with Nomura et $a l^{12)}$

\subsection{Impact of Potassium on the Degree of Burning-off of Ferro-Coke}

It is seen from Fig. 3(a) for ferro-coke without $\mathrm{K}$ addition (sample B-1), the degree of burning-off of $7200 \mathrm{~s}$ was $4.59 \%, 6.28 \%$ and $12.64 \%$ at $950^{\circ} \mathrm{C}, 1000^{\circ} \mathrm{C}$ and $1050^{\circ} \mathrm{C}$, respectively. While it is seen from Fig. 3(b) for ferro-coke with $\mathrm{K}$ addition (sample B-2) the degree of burning-off was respectively $7.99 \%, 10.17 \%$ and $8.99 \%$ higher at these three temperatures, respectively, demonstrating that potassium has a strong catalytic effect on gasification reaction of ferro-coke.

\subsection{Influence of Potassium on Reactivity and Post- Reaction Strength of Ferro-Coke}

The reactivity and post-reaction strength of coke were measured with use of the Tablets Coke Method, the results

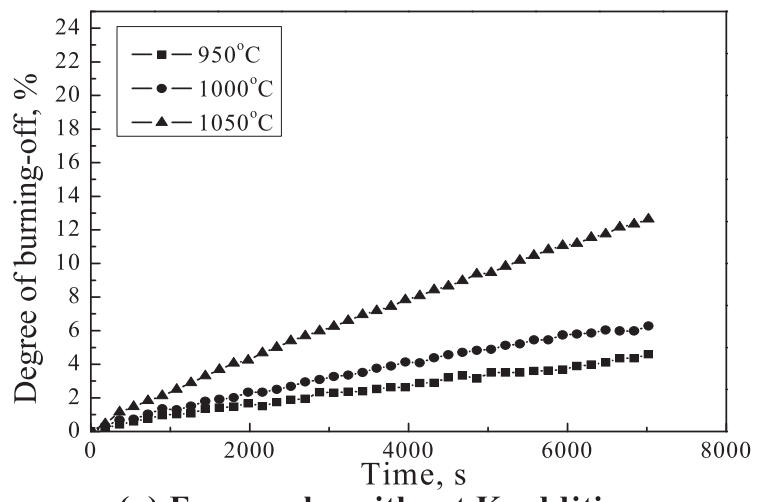

(a) Ferro-coke without $\mathrm{K}$ addition

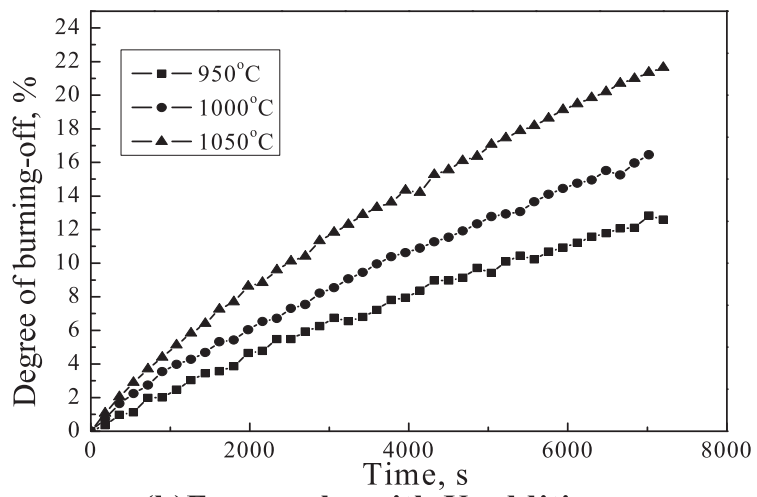

(b)Ferro-coke with $\mathrm{K}$ addition

Fig. 3. Plot of the degree of burning-off of B-1 (without K addition) and B-2 (with $\mathrm{K}$ addition) vs time.

are shown in Fig. 4. It can be known from Fig. 4(a) that for the case of without $\mathrm{K}$ addition, $\mathrm{CRI}_{\mathrm{TCM}}$ of ferro-coke was roughly twice that of traditional coke while $\mathrm{CSR}_{\mathrm{TCM}}$ of ferro-coke was about $18 \%$ lower than that of traditional coke.

It is also known from Fig. 4(a) that for both types of coke, $\mathrm{CRI}_{\mathrm{TCM}}$ apparently increased while $\mathrm{CSR}_{\mathrm{TCM}}$ apparently decreased with the $\mathrm{K}_{2} \mathrm{O}$ content increasing. When the $\mathrm{K}_{2} \mathrm{O}$ content reached $3.26 \%$, the extent of $\mathrm{CRI}_{\mathrm{TCM}}$ increasing of two cokes were nearly the same $(44.75 \%$ and $41.93 \%$ for traditional coke and ferro-coke, respectively), and so does the extent of $\mathrm{CSR}_{\mathrm{TCM}}$ decreasing of two cokes $(61.03 \%$ and $64.54 \%$ for traditional coke and ferro-coke, respectively), implying the catalytic activity of $\mathrm{Fe}$ and $\mathrm{K}$ are essentially independent from each other. This conclusion also agrees well with Nomura et al. ${ }^{12)}$

Nevertheless, when the $\mathrm{K}_{2} \mathrm{O}$ content reached $3.26 \%$, the post-reaction strength of ferro-coke became extremely poor and the sample was in a powered form, but traditional coke still kept its original shape. Why potassium makes coke strength worse ${ }^{10)}$ is not only because it promotes carbon gasification, but also because it could form interlamination compounds such as $\mathrm{KC}_{60}, \mathrm{KC}_{8}$, etc. When $\mathrm{KC}_{8}$ is formed, the volumetric expansion of coke could be as high as $61 \%$, inducing the generation of cracks in coke grains.

As also shown in Fig. 4(b) that there is a good linear relation between $\mathrm{CSR}_{\mathrm{TCM}}$ and $\mathrm{CRI}_{\mathrm{TCM}}$ for both the cokes, but the scope (absolute value) for ferro-coke was slightly bigger. 


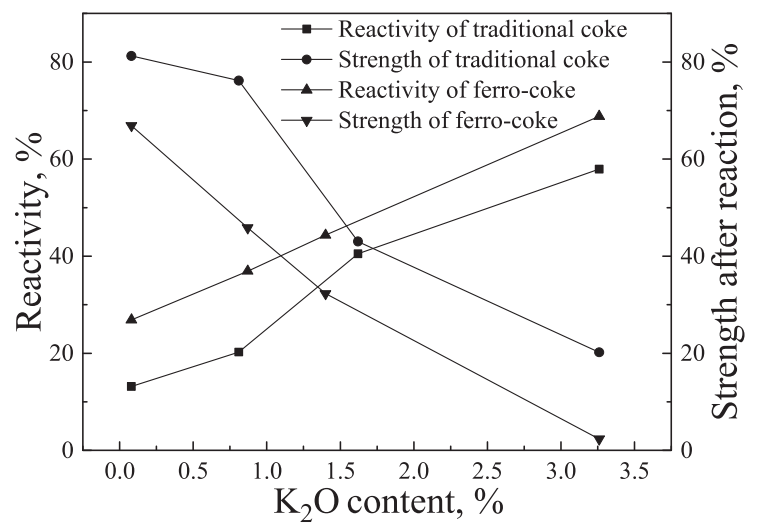

(a)Compact of potassium

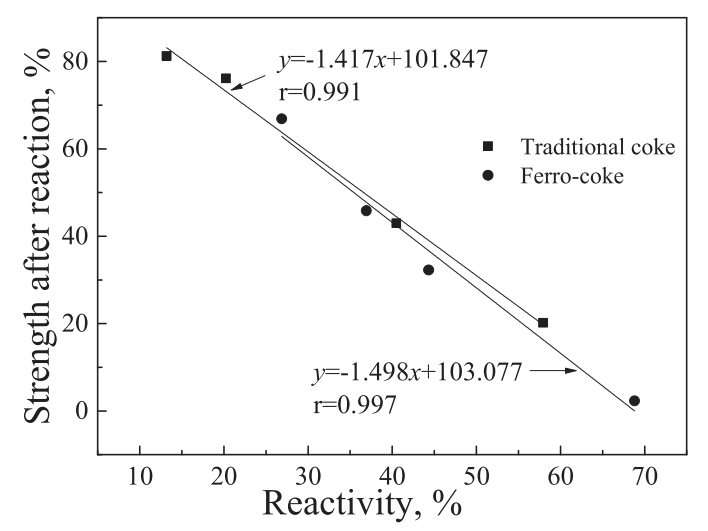

(b)Relationship between CRI $\mathrm{ICM}_{\mathrm{TCM}}$ and $\mathrm{CSR}_{\mathrm{TCM}}$

Fig. 4. The thermal properties of traditional coke and ferro-coke.

\subsection{Influence of Potassium on Reaction Kinetics of Ferro-Coke}

\subsubsection{Establishment of Reaction Rate Equations}

The reaction of ferro-coke with $\mathrm{CO}_{2}$ belongs to a gas/ solid reaction, and according to the theory of SCM, the total resistance of reaction consists of three parts, i.e. the mass transfer of gases within the boundary layer, the interior diffusion of gases and the chemical reaction at the interfaces. When reaction reaches a stable state, the velocity of these three steps are identical, further, due to the very large equilibrium constants of coke gasification reaction $(K=32.8$, $121.5,372.4$ and 978.5 at 900, 1000,1050 and $1100^{\circ} \mathrm{C}$, respectively), a simplified equation for the general reaction rate $r_{A}$ is derived: ${ }^{21)}$

$$
r_{A}=\frac{4 \pi r_{p}^{2}\left(c-c_{e}\right)}{\frac{1}{k_{g}}+\frac{r_{p}}{D_{e}} \cdot \frac{r_{p}-r_{i}}{r_{i}}+\frac{K}{k_{+}(1+K)} \cdot \frac{r_{p}^{2}}{r_{i}^{2}}}
$$

where $r_{p}$ and $r_{i}$ are respectively the original radius of sample and the radius of reaction interface, $\mathrm{m} ; c$ and $c_{e}$ are respectively the $\mathrm{CO}_{2}$ concentration inside the gas phase and the one at equilibrium, $\mathrm{mol} / \mathrm{m}^{3} ; k_{g}$ is the mass transfer coefficient in the gas boundary layer, $\mathrm{m} / \mathrm{s} ; D_{e}$ is the effective diffusion coefficient of gases in the porous products layer, $\mathrm{m}^{2} / \mathrm{s} ; k_{+}$is the velocity of the positive reaction, $\mathrm{m} / \mathrm{s} ; K$ is the equilibrium constant of gasification reaction.

Since the degree of burning-off $R=1-\left(r_{i} / r_{p}\right)^{3}$, its relationship with time $t$ can be obtained by integrating Eq. (4) and
Table 6. $\mu_{m i x}, D_{\mathrm{CO}_{2}}$ and $k_{g}$ at different reaction temperatures.

\begin{tabular}{cccc}
\hline $\begin{array}{c}\text { Temperature } \\
(\mathrm{K})\end{array}$ & 1223 & 1273 & 1323 \\
\hline$\mu_{m i x}(\mathrm{~Pa} . \mathrm{s})$ & $4.523 \times 10^{-5}$ & $4.653 \times 10^{-5}$ & $4.812 \times 10^{-5}$ \\
$D_{\mathrm{CO}_{2}}\left(\mathrm{~m}^{2} / \mathrm{s}\right)$ & $1.748 \times 10^{-4}$ & $1.854 \times 10^{-4}$ & $1.989 \times 10^{-4}$ \\
$k_{g}(\mathrm{~m} / \mathrm{s})$ & $4.893 \times 10^{-2}$ & $5.168 \times 10^{-2}$ & $5.507 \times 10^{-2}$ \\
\hline
\end{tabular}

expressed as the following equation:

$$
\begin{aligned}
t & =\frac{\rho_{0} r_{p}}{c-c_{e}}\left\{\frac{R}{3 k_{g}}+\frac{r_{p}}{6 D_{e}}\left[1-3(1-R)^{2 / 3}+2(1-R)\right]\right. \\
& \left.+\frac{1}{k_{+}}\left[1-(1-R)^{1 / 3}\right]\right\}
\end{aligned}
$$

where $\rho_{0}$ is the mole density of fixed carbon in ferro-coke, $\mathrm{mol} / \mathrm{m}^{3}$.

Further, let $F=1-(1-R)^{1 / 3}$, Eq. (6) is finally concluded:

$$
\frac{t-t_{1}}{F}=A\left(3 F-2 F^{2}\right)+B
$$

where,

$$
\begin{gathered}
t_{1}=\frac{R r_{p} \rho_{0} \psi^{1 / 2}}{3 k_{g}\left(c-c_{e}\right)} . \\
A=\frac{\rho_{0} r_{p}^{2} \psi}{6 D_{e}\left(c-c_{e}\right)} . \\
B=\frac{r_{p} \rho_{0} \psi^{1 / 2}}{k_{+}\left(c-c_{e}\right)}
\end{gathered}
$$

Because the shape of the sample is not regular, the shape coefficient $\psi$ is introduced, and it can be evaluated by Eq. $(10):^{22)}$

$$
\psi=0.390 \log \left(1000 d_{p}\right)+0.161
$$

where, $d_{p}$ is the equivalent diameter of ferro-coke, $\mathrm{m}$. In this work, the value of $\psi$ is 0.625 .

At the specified experimental temperatures, $c_{e}$ is near zero. $k_{g}$ is computed with the Lanz-Marshall equation, yet two dimensionless numbers $R e$ and $S c$ are to be firstly determined, and for this purpose it is required to calculate gaseous viscosity $\mu_{m i x}{ }^{23)}$ and the molecular diffusion coefficient $D_{\mathrm{CO}_{2}}{ }^{24)}$ of carbon dioxide in the $\mathrm{CO}_{2}-\mathrm{CO}-\mathrm{N}_{2}$ system at the gas boundary layer. The calculated results for $950^{\circ} \mathrm{C}$, $1000^{\circ} \mathrm{C}$ and $1050^{\circ} \mathrm{C}$ are listed in Table 6 .

For every test, $k_{g}$ is obtained by referring to Table 6 , and $t_{1}$ is attained by substituting $k_{g}$ into Eq. (7). The intrinsic relation between the degree of burning-off and interior diffusion, and that between the degree of burning-off and the interface chemical reaction could thus be discovered by applying data from a group of experiments to Eq. (6).

\subsubsection{Evaluation of Reaction Rate Constant and Interior Diffusion Coefficient}

By converting the data observed at $950^{\circ} \mathrm{C}, 1000^{\circ} \mathrm{C}$ and $1050^{\circ} \mathrm{C}$, Fig. 5 could be obtained with plotting $\left(t-t_{1}\right) / F$ against $3 F-2 F^{2}$ according to Eq. (6). 
It is revealed from Fig. 5 that good linear relations appear between $\left(t-t_{1}\right) / F$ and $3 F-2 F^{2}$ at all these temperatures, stating the application of the SCM of mixed control to the analysis of the gasification reaction kinetics of ferro-coke is appropriate. By using Eqs. (8) and (9) and data in Fig. 5, $D_{e}$ and $k_{+}$could be evaluated, see Table 7 . As can be seen that $D_{e}$ as well as $k_{+}$increase with a rising of temperature.

\subsubsection{Calculation of Activation Energies}

With respect to $k_{+}$and $D_{e}$, the Arrhenius Equation was respectively rewritten, and their values in Table 5 were substituted into Eqs. (11) and (12), respectively. By plotting $\ln k_{+}$and $\ln D_{e}$ against $1 / T$, respectively, four fitting lines as shown in Fig. 6 were attained.

$$
\ln k_{+}=-\frac{E_{a}}{R T}+A
$$

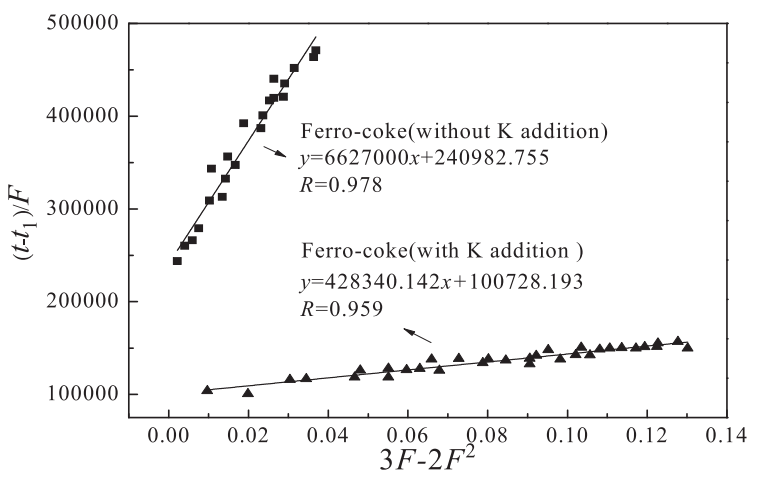

(a) $950^{\circ} \mathrm{C}$

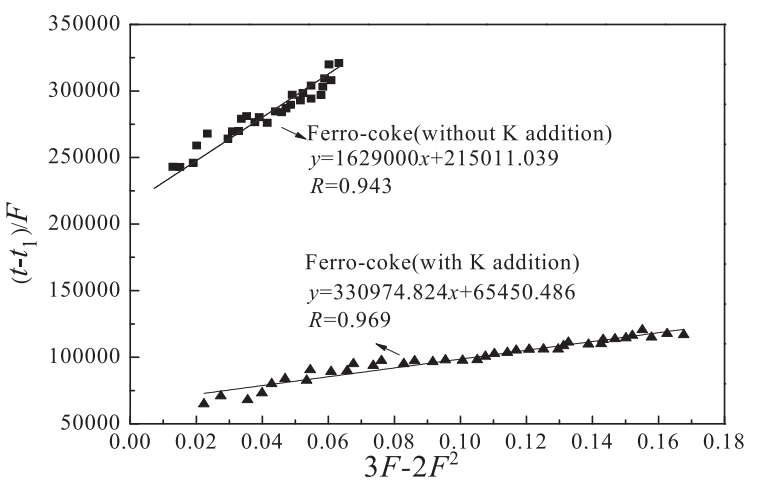

(b) $1000^{\circ} \mathrm{C}$

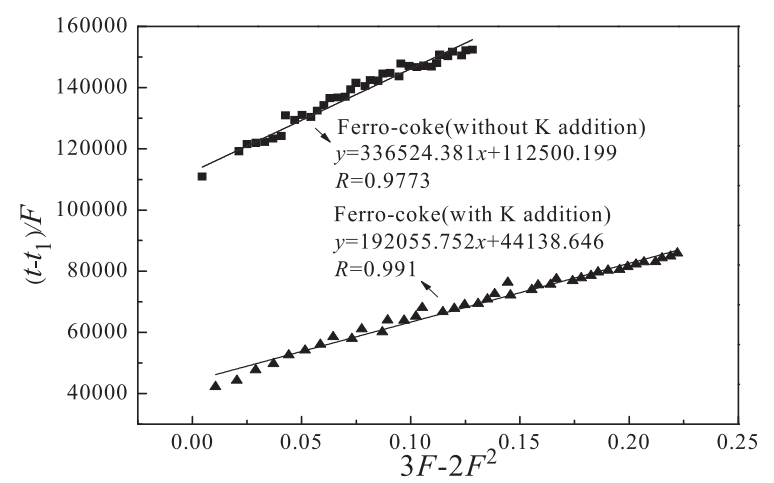

(c) $1050^{\circ} \mathrm{C}$

Fig. 5. Relationship between $\left(t-t_{1}\right) / F$ and $\left(3 F-2 F^{2}\right)$ for ferro-coke without $\mathrm{K}$ addition (B-1) and with $\mathrm{K}$ addition (B-2).

$$
\ln D_{e}=-\frac{E_{D}}{R T}+A^{\prime}
$$

where $A$ and $A^{\prime}$ are the pre-exponent factor of $E_{a}$ and $E_{D}$, respectively.

It is known that when $n$ is equal to 3 and significance level is 0.10 , the critical value of $r$ is equal to 0.987 , showing the requirement of significance examination is satisfied. Therefore, $E_{a}$ and $E_{D}$ could be evaluated from the slope and intercept of Figs. 6(a) and 6(b), respectively. The results are listed in Table 8.

It is known from Table 8, compared to B-1, $E_{a}$ of B-2 was $4.57 \mathrm{~kJ} / \mathrm{mol}$ smaller while $E_{D}$ of B-2 was $94.5 \mathrm{~kJ} / \mathrm{mol}$ smaller. From this it follows that at $0.95 \% \mathrm{~K}_{2} \mathrm{O}$, the catalytic effect of potassium reduced the two activation energies, $E_{D}$ in particular. The reduction of $E_{a}$ and $E_{D}$ made ferro-coke gasify at higher velocities and at lower temperatures, and thus brought about a decrease of starting gasification temperature. This explains well the observed results, see Fig. 2.

The authors made an effort to compare the kinetics parameters acquired in this work with the literature. For increasing comparability, only Reference [16] was cited. In

Table 7. $D_{e}$ and $k_{+}$of gasification reaction at different temperatures of ferro-coke samples.

\begin{tabular}{ccccc}
\hline \multirow{2}{*}{$\begin{array}{c}\text { Temperature } \\
(\mathrm{K})\end{array}$} & \multicolumn{2}{c}{$\mathrm{B}-1$} & \multicolumn{2}{c}{$\mathrm{B}-2$} \\
\cline { 2 - 5 } & $D_{e}\left(\mathrm{~m}^{2} / \mathrm{s}\right)$ & $k_{+}(\mathrm{m} / \mathrm{s})$ & $D_{e}\left(\mathrm{~m}^{2} / \mathrm{s}\right)$ & $k_{+}(\mathrm{m} / \mathrm{s})$ \\
\hline 1223 & $3.113 \times 10^{-8}$ & $6.955 \times 10^{-4}$ & $3.575 \times 10^{-7}$ & $1.845 \times 10^{-3}$ \\
1273 & $9.784 \times 10^{-8}$ & $9.002 \times 10^{-4}$ & $4.816 \times 10^{-7}$ & $2.957 \times 10^{-3}$ \\
1323 & $4.922 \times 10^{-7}$ & $1.788 \times 10^{-3}$ & $8.623 \times 10^{-7}$ & $4.556 \times 10^{-3}$ \\
\hline
\end{tabular}
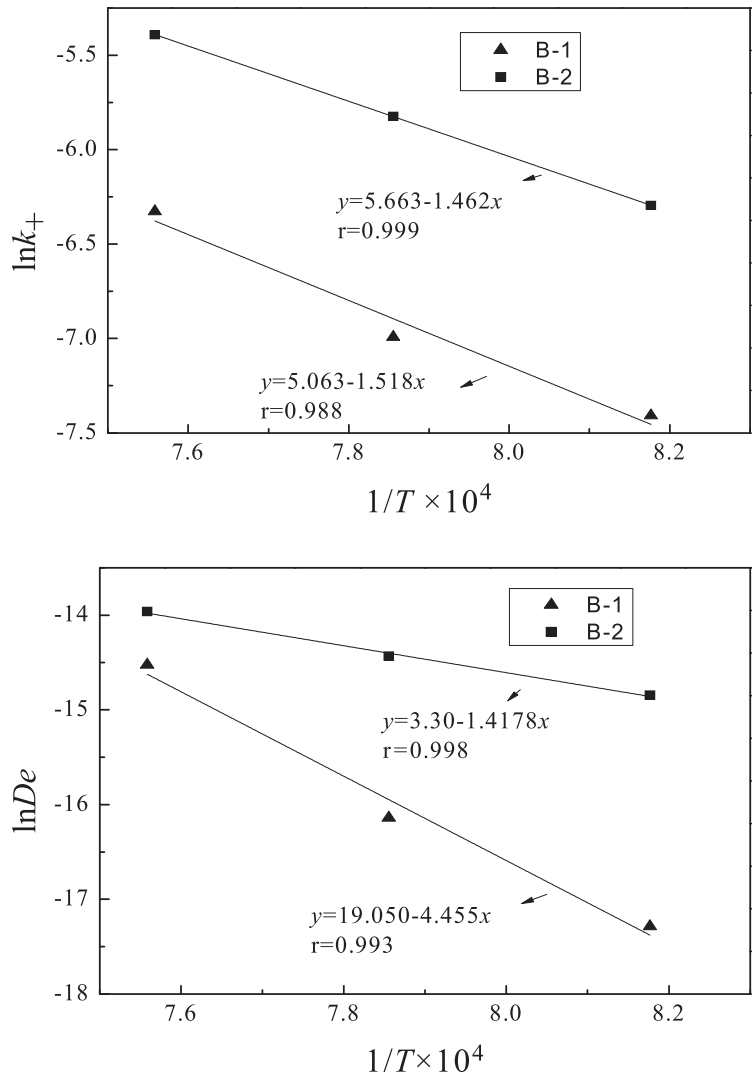

Fig. 6. Relationship between $\ln k_{+}$and $1 / T, \ln D_{e}$ and $1 / T$ for ferrocoke without K (B-1) addition and with K addition (B-2). 
this work, the specimens in form of piece were used, gasification reaction experiments were isothermal, and the SCM was also applied as the basis of kinetics analysis. The properties of coke samples in this comparison are given in Table 9. The results from comparison are given in Table $\mathbf{1 0}$.

The quite obvious difference in $E_{a}$ and $E_{D}$ between traditional coke $\left(\mathrm{CO}_{2}\right)$ and ferro-coke without $\mathrm{K}$ addition $\left(\mathrm{CO}_{2}+\mathrm{CO}+\mathrm{N}_{2}\right)$ as shown in Table 10 can be attributed to the difference in gas composition accepted in the gasification reaction kinetics experiment, see section 2.4.

In comparison with the industrial coke, $E_{a}$ of traditional coke is apparently larger $(183.124 \mathrm{~kJ} / \mathrm{mol}$ and $124.5 \mathrm{~kJ} / \mathrm{mol}$ respectively), this is possibly because the traditional coke is prepared by stamping charge coke making and its apparent density is bigger $\left(1.02 \mathrm{t} / \mathrm{m}^{3}\right.$ and $0.950 \mathrm{t} / \mathrm{m}^{3}$ respectively), unfavorable to the proceeding of gasification reaction. As for $E_{D}$, the industrial coke is greatly bigger than the traditional coke $(642.4 \mathrm{~kJ} / \mathrm{mol}$ and $392.005 \mathrm{~kJ} / \mathrm{mol}$ respectively), this is probably caused by the higher resistance of ash layer of industrial coke to gases flow during gasification.

It is known that temperature at beginning of softening and deformation of coke ash is usually lower than $1250^{\circ} \mathrm{C}$. Therefore, it would be presumed that the temperature at beginning of softening and deformation of ash in the industrial coke is relatively low and thus some ash generated during $\mathrm{CO}_{2}$ gasification of the industrial coke softened and melted within its experimental temperature range of 1016 to $1272^{\circ} \mathrm{C}$, leading to a substantial increase of resistance in ash layer to the reaction gases flow, as a result, $E_{D}$ becomes very big.

\subsubsection{Resistance in the Different Steps of Gasification Reaction}

The mass transfer resistance in the boundary layer $\eta_{g}$,

Table 8. $E_{a}$ and $E_{D}$ of original and $\mathrm{K}$ added ferro-cokes.

\begin{tabular}{ccc}
\hline Sample & $E_{a}(\mathrm{~kJ} / \mathrm{mol})$ & $E_{D}(\mathrm{~kJ} / \mathrm{mol})$ \\
\hline B-1 & 125.949 & 369.787 \\
B-2 & 121.384 & 275.287 \\
\hline
\end{tabular}

interior diffusion resistance $\eta_{D}$ and interface chemical reaction resistance $\eta_{r}$ of coke gasification reaction are calculated according to Eqs. (13) to (15), and the percentage of these resistances in the total resistance are calculated according to Eq. (16), the results are demonstrated in Fig. 7.

$$
\begin{gathered}
\eta_{g}=\frac{1}{k_{g}} \ldots \ldots \ldots \ldots . . . . . \\
\eta_{D}=\frac{r_{p}}{D_{e}}\left[(1-R)^{-1 / 3}-1\right] \\
\eta_{r}=\frac{1}{k_{+}}(1-R)^{-2 / 3} \ldots \ldots \\
f_{\eta_{i}}=\frac{\eta_{i}}{\eta_{D}+\eta_{r}+\eta_{g}} \times 100 \%
\end{gathered}
$$

where $\eta_{i}$ is respectively $\eta_{D}, \eta_{r}$ and $\eta_{g}, i=1,2,3$.

It is seen from Fig. 7 that $f_{\eta g}$ is consistently very small whether for original ferro-coke or ferro-coke with potassium addition. This is because the $\mathrm{CO}_{2}$ flow rate accepted in the tests is large and the influence of external diffusion is small. It is known from Fig. 7(a) that for original ferrocoke without $\mathrm{K}$ addition, as temperature is increased from $950^{\circ} \mathrm{C}$ to $1050^{\circ} \mathrm{C}$, the interval of the $f_{\eta r}$ curve and the $f_{\eta D}$ curve is shortened by a large margin. This is because $E_{D}$ of original ferro-coke is nearly three folds of $E_{a}$, stating that with a same increase of temperature, the extent of interior diffusion improving remarkably exceeds that of chemical reaction improving, and therefore the interval between the $f_{\eta D}$ curve and the $f_{\eta r}$ curve is shorten.

As can been seen from Fig. 7(b), however, for ferrocoke with $\mathrm{K}$ addition, increasing temperature almost has no impact on the $f_{\eta D}$ curve as well as on the $f_{\eta r}$ curve. The two $f_{\eta D}$ curves are almost overlapped, and so does the two $f_{\eta r}$ curves, showing that $f_{\eta D}$ as well as $f_{\eta r}$ are almost only related to the degree of burning-off. This phenomenon is

\begin{tabular}{|c|c|c|c|c|c|c|c|c|c|}
\hline Researchers & Samples & $\mathrm{A}_{\mathrm{d}} \operatorname{mass} \%$ & $\mathrm{~K}_{2} \mathrm{O}$ mass $\%$ & T.Fe mass $\%$ & $d \mathrm{t} / \mathrm{m}^{3}$ & $\rho_{a} \mathrm{~g} \cdot \mathrm{cm}^{-3}$ & $\rho_{t} \mathrm{~g} \cdot \mathrm{cm}^{-3}$ & $P_{t} \mathrm{vol} \%$ & $P_{a} \mathrm{vol}^{2} \%$ \\
\hline Cui, et al. ${ }^{16)}$ & Industrial coke & 11.7 & - & - & - & 0.950 & - & - & - \\
\hline This work & Traditional coke & 13.44 & 0.10 & 0.60 & 1.1 & 1.02 & 1.96 & 47.76 & 38.03 \\
\hline This work & Ferro-coke & 25.47 & 0.081 & 9.02 & 1.1 & 1.07 & 2.12 & 49.5 & 41.53 \\
\hline
\end{tabular}
possibly because potassium increases the number of pores and enlarges pores of ferro-coke substantially, which is

Table 9. Properties of the coke samples used by different researchers.

\begin{tabular}{|c|c|c|c|c|c|c|c|c|}
\hline Sample & $\mathrm{K}_{2} \mathrm{O}$ mass $\%$ & Size mm & Temp. ${ }^{\circ} \mathrm{C}$ & Gas & $E_{a} \mathrm{~kJ} / \mathrm{mol}$ & $A \min ^{-1}$ & $E_{D} \mathrm{~kJ} / \mathrm{mol}$ & $A^{\prime} \min ^{-1}$ \\
\hline Industrial coke ${ }^{16)}$ & Unknown & $19-21$ & $1016-1272$ & Pure $\mathrm{CO}_{2}$ & 124.5 & - & 642.4 & - \\
\hline Traditional coke* & 0.10 & $10-12.5$ & $950-1050$ & Pure $\mathrm{CO}_{2}$ & 183.124 & 9.848 & 392.005 & 21.978 \\
\hline \multirow{2}{*}{ Ferro-coke* } & 0.081 & $10-12.5$ & $950-1050$ & $\mathrm{CO}_{2}+\mathrm{CO}+\mathrm{N}_{2}$ & 125.949 & 5.063 & 369.787 & 19.050 \\
\hline & $0.941^{* *}$ & $10-12.5$ & $950-1050$ & $\mathrm{CO}_{2}+\mathrm{CO}+\mathrm{N}_{2}$ & 121.384 & 5.663 & 275.287 & 3.30 \\
\hline
\end{tabular}

Note: $d$ is the bulk density of coal charge, $\rho_{a}$ is the apparent density, $\rho_{t}$ is the true density; $P_{t}$ is the total porosity, $P_{a}$ is the open porosity.

Table 10. Kinetics parameters of coke gasification reaction reported by different researchers.

*: this work;

**: with $\mathrm{K}$ addition 


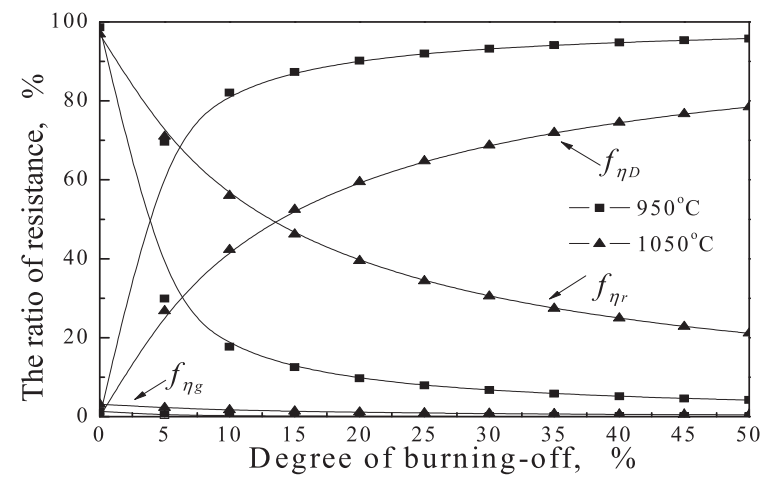

(a)Ferro-coke without $\mathrm{K}$ addition(B-1)

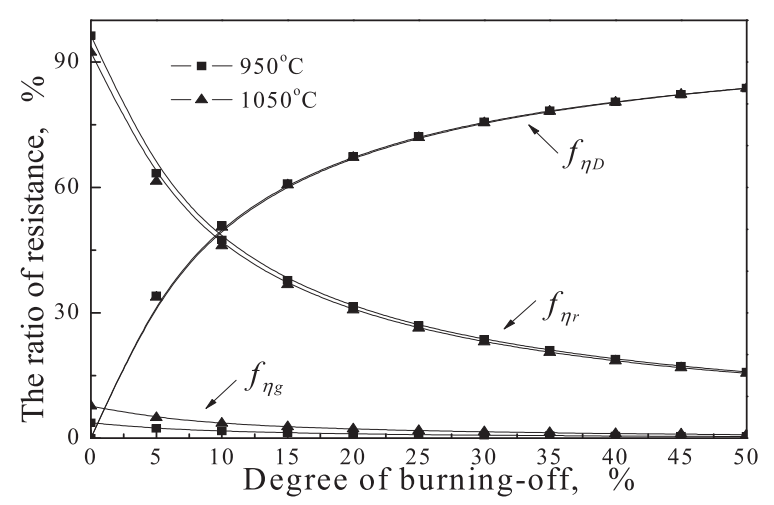

(b)Ferro-coke with $\mathrm{K}$ addition(B-2)

Fig. 7. Relationship between the ratio of resistance of various steps and the degree of burning-off of ferro-coke.

favorable to interior diffusion, as a result, the importance of temperature increasing becomes smaller in terms of improving the interior diffusion.

By comparing Fig. 7(a) with Fig. 7(b), it is revealed that, for original ferro-coke without $\mathrm{K}$ addition, reaction is essentially controlled by interior diffusion $\left(f_{\eta D}\right.$ is as high as over $90 \%$ ) at $950^{\circ} \mathrm{C}$ when the degree of burning-off exceeds $20 \%$, but reaction is typically mixed controlled at $1050^{\circ} \mathrm{C}$ when the degree of burning-off is until $50 \%$. For ferro-coke with $\mathrm{K}$-addition, however, at both $950^{\circ} \mathrm{C}$ and $1050^{\circ} \mathrm{C}$, reaction is typically mixed controlled.

\section{Conclusions}

(1) When the $\mathrm{K}_{2} \mathrm{O}$ content was increased to $0.95 \%$, the starting gasification temperature of ferro-coke dramatically decreased while it decreased slowly as the $\mathrm{K}_{2} \mathrm{O}$ content further increased. In respect to promoting gasification, the effect of potassium on ferro-coke is substantially weaker than on traditional coke.

(2) When no $\mathrm{K}$ was added, $\mathrm{CRI}_{\mathrm{TCM}}$ of ferro-coke was twice that of traditional coke while $\mathrm{CSR}_{\mathrm{TCM}}$ of ferro-coke was about $18 \%$ lower than that of traditional coke. With a same amount of potassium added, the evolution behavior of the thermal properties of both types of coke was similar, but the slope (absolute value) of curve of $\mathrm{CSR}_{\mathrm{TCM}}$ against $\mathrm{CRI}_{\mathrm{TCM}}$ of ferro-coke is slightly greater.

(3) Adding potassium makes the activation energies of ferro-coke gasification reaction decrease, mainly the diffusion activation energy: $E_{a}$ and $E_{D}$ of ferro-coke without K addition was respectively 125.949 and $369.787 \mathrm{~kJ} / \mathrm{mol}$ while
$E_{a}$ and $E_{D}$ of ferro-coke with $\mathrm{K}$ addition were respectively 121.384 and $275.287 \mathrm{~kJ} / \mathrm{mol}$.

(4) Gasification kinetics of ferro-coke was highly affected by potassium impregnation. For ferro-coke without $\mathrm{K}$ addition, the control step was simply interior diffusion at $950^{\circ} \mathrm{C}$ when the degree of burning-off exceeds $20 \%$, but reaction became mixed controlled by chemical reaction and interior diffusion at $1050^{\circ} \mathrm{C}$. For ferro-coke with $\mathrm{K}$ addition, however, reaction was always mixed controlled from $950^{\circ} \mathrm{C}$ through $1050^{\circ} \mathrm{C}$. Moreover, different from ferrocoke without $\mathrm{K}$ addition, the ratio of chemical reaction resistance as well as the ratio of interior diffusion resistance for ferro-coke with $\mathrm{K}$ addition was not related to temperature but only related to the degree of burning-off.

\section{Acknowledgements}

The National Natural Science Foundation of China (NFSC) provided financial support to this work (Project No.: 51174149). The authors are grateful to Mr. Teng YING and Shang-guo LIANG of the Wuhan Iron and Steel Company, Ltd. for invaluable advices and help during the study.

\section{REFERENCES}

1) S. Gupta, B. C. Kim, M. Grigore, D. French, R. Sakurovs and V. Sahajwalla: Proc., Iron \& Steel Technology Conf. and Exposition (AISTech 2007), AIST, Warrendale, PA, (2007), 101.

2) A. Sharma, K. Uebo and Y. Kubota: Tetsu-to-Hagané, 96 (2010), 280.

3) M. Naito, A. Okamoto, K. Yamaguchi, T. Yamaguchi and Y. Inoue: Tetsu-to-Hagané, 87 (2001), 357.

4) S. Nomura, S. Matsuzaki, M. Naito, H. Ayukawa, S. Koizumi, Y. Ogata, T. Nakayama, T. Abe, H. Kitaguchi and T. Tahara: Proc., Iron \& Steel Technology Conf. and Exposition (AISTech 2006), AIST, Warrendale, PA, (2006), 31.

5) S. Nomura, H. Terashima, E. Sato and M. Naito: ISIJ Int., 47 (2007), 823.

6) M. Sato, H. Matsuno and K. Ishii: Proc. Asia Steel Int. Conf. 2015, ISIJ, Tokyo, (2015), 6A-1L1.

7) A. K. Biswas: Principles of Blast Furnace Iron Making, Cootha Publishing House, Brisbane, Australia, (1981), 249.

8) M. Hatano, T. Miyazaki and Y. Iwanaga: Trans. Iron Steel Inst. Jpn., 20 (1980), 592.

9) S. Long: Ironmaking, 4 (1985), No. 3, 1 (in Chinese).

10) W.-K. Lu, G. Samman and M. Uribe: Coke Reactivity and its Effect on Blast Furnace Operation, Iron and Steel Society, Warrendale, PA, (1990), 75

11) K. Kojima, T. Nishi, T. Yamaguchi, H. Nakama and S. Ida: Trans. Iron Steel Inst. Jpn., 16 (1976), 570.

12) S. Nomura, K. Higuchi, K. Kunitomo and M. Naito: ISIJ Int., 50 (2010), 1388.

13) J. Szekely and D. A. Aderibigbe: Coke Reactivity and its Effect on Blast Furnace Operation, Iron and Steel Society, Warrendale, PA, (1990), 3.

14) A. S. Jayasekara, B. J. Monaghan and R. J. Longbottom: Fuel, 154 (2015), 45.

15) X. Huang: Principal of Ferrous Metallurgy, Metallurgical Industry Publisher, Beijing, (2014), 137.

16) P. Cui, L. Zhang, M. Yang and Y. Wang: J. Fuel Chem. Technol., 34 (2006), 280.

17) S. Nomura, H. Kitaguchi, K. Yamaguchi and M. Naito: ISIJ Int., 47 (2007), 245.

18) S. Nomura, M. Naito and K. Yamaguchi: ISIJ Int., 47 (2007), 831.

19) S. Nomura: ISIJ Int., 54 (2014), 2533.

20) P. Li, X. Bi, S. Shi, H. Zhang and J. Zhou: J. Iron Steel Res., 27 (2015), 10.

21) X. Xiao and R. Xie: Reaction Engineering in Metallurgy, Metallurgical Industry Publisher, Beijing, (1997), 22.

22) M. Chida, K. Tamura, Y. Hayashi and Y. Isozaki: Tetsu-to-Hagané, 73 (1987), 748.

23) R. B. Bird, W. E. Stewart and E. N. Lightfoot: Transport Phenomena, 2nd Ed., John Wiley \& Sons, New York, (2002), 25.

24) Y. Omori: Blast Furnace Phenomena and Modelling, Elsevier Applied Science Publishers, New York, (2007), 123. 